of two tons to the acre produced no beneficial results.

Pot plants treated with bacterised peat show, as compared with controls, not only increased growth but sturdier habit and greater rootdevelopment. This fact led to the suggestion that the phenomena cannot be attributed solely to the nitrogen-content of the fertiliser. It is, for example, a well-known fact that the addition of phosphorus-containing fertilisers brings about the development of a more vigorous root-system than is produced in soil poor in available phosphates.

Following up the suggestion that the virtues of bacterised peat are to be sought elsewhere than in the nitrogen contained in the fertiliser, Prof. Bottomley was led to the very interesting conclusion that the growth of plants is conditioned not only by the well-known substance-producing critical spirit that we confess that the evidence does not appear to us strong enough to bear its burden. Biologists need no reminder of the pitfalls that beset their attempts to establish hypotheses by the method of comparison. Although often the only method at our service, it is a very clumsy one; and in a subject of such importance as the existence of a new type of food substances, the evidence must be overwhelmingly strong before the hypothesis which it supports may be accepted.

We do not think that Prof. Bottomley's evidence is strong enough to support this test. Nevertheless, it should not be dismissed lightly; rather is it a case like so many in biological science, in which a just judge would order a fresh trial. We understand that such a trial is to be conducted at Rothamsted, and we hope, for the sake of horticulture and agriculture, that it may lead on one

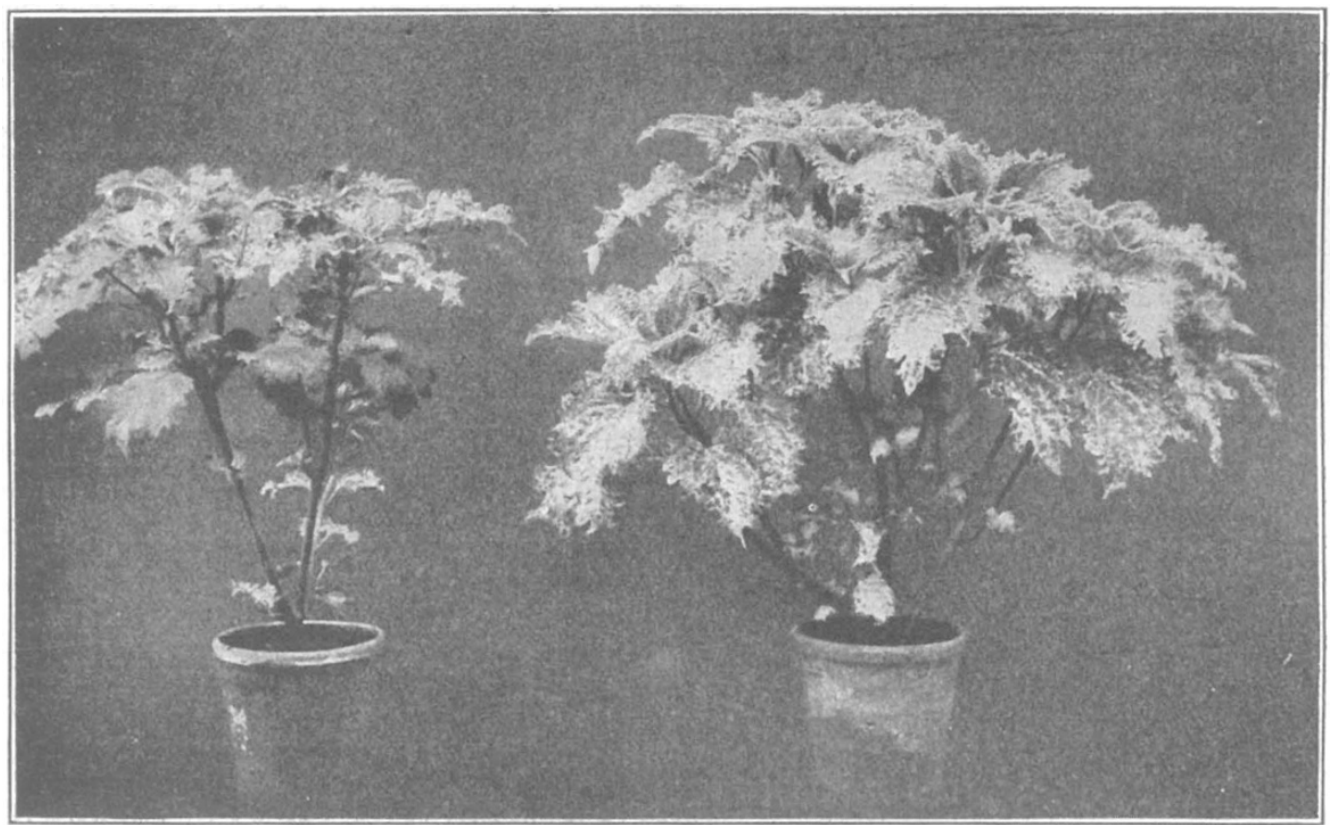

FIG. 2.-Two specimens of coleus grown at the Koyal Gardens, Kew. The right-hand plant received humogen, while the left had the usual potting compost. From "The Spirit of the Soil."

food materials, but also by hitherto unknown growth stimulators. These substances, which he claims to have isolated from peat, Prof. Bottomley has called auximones. He believes that they play a part in plant-nutrition somewhat similar to that played by accessory food bodies in the nutrition of animals.

Like Prospero, who at first called up the wrong kind of spirit, but succeeded on a second attempt, Prof. Bottomley's wand first evoked nitrogen, but now waives that heavy apparition in favour of a more delicate, Ariel-like auximone. Auximones are "it," in the vulgar parlance of the day, or in the more elegant language of Mr. Knox they are the spirit of the soil.

Prof. Bottomley brings forward evidence in favour of the existence of auximones and of the important part they play in activating the growth of plants. It is, however, in no hyper- hand to the demonstration of the fertilising value of bacterised peat, and on the other to the just judgment of the case for auximones.

FREDERICK KeEBLE.

\section{DYSENTERY AND WAR}

DSENTERY is a term embracing several varieties of intestinal flux. Anatomically there is inflammation, and frequently ulceration of the large bowel. Owing to improved sanitary conditions the diseases described under dysentery have become infrequent in this country, though outbreaks occasionally occur, particularly in overcrowded institutions. In the past, however, widespread epidemics have prevailed, notably one which raged between 1847 and 1856 ; and in the tropics dysentery still deserves its
No. 2406, VOL. 96] 
reputation as being one of the most destructive of diseases.

Dysentery, moreover, is one of the great diseases attacking camps, and has been more destructive to armies than powder and shot (Osler). In the Federal service during the Civil War, according to Woodward, there were 259,07 I cases of acute and $28,45^{\mathrm{I}}$ cases of chronic dysentery, and the disease prevailed widely in the South African campaign, in the Frarco-German War of 1870, in the Crimean War, and even before the Battle of Agincourt in $\mathrm{r}_{4} \mathrm{r}$. In the present campaign, too, dysentery has prevailed both in the Western and Eastern seats of warin Gallipoli, for example, in the course of a few months some 78 ,ooo men were invalided on account of sickness, a large proportion of whom suffered from this disease.

The two principal types of dysentery are the amcebic and the bacillary, due respectively to an amcebiform protozoon and to a group of closelyallied bacteria, the dysentery bacilli. Amœbic dysentery or "amœbiasis" is essentially a disease of the subtropical and tropical regions of the globe, and is widespread over the continents of Africa, Asia, and America, and is particularly common in Egypt and India. The causative parasite, the Entamoeba histolytica, is met with as an organism resembling an ordinary amœba in the mucus passed in the acute stage of the disease, and in the liver abscesses which frequently complicate the disease. In this stage it is actively motile, and has a diameter of I/IOoo$\mathbf{I} / 600$ in. It has also an encysted resting stage, found in the intervals between attacks and in latent cases.

Bacillary dysentery, on the other hand, is of world-wide distribution, and is apt to occur in epidemics, thus differing from amobic dysentery. Ogata first isolated and described a dysentery bacillus in Japan; this was followed by researches by Shiga in the same country in 1898 , and by Kruse in Germany. They proved that the bacillus is a specific one, and it was shown later that it was the same bacillus which is now known as the Bacillus dysenteriae of Shiga and Kruse. Later other varieties were isolated by Flexner and by Strong in the Philippines, and by Hiss and Russell (the Y-bacillus).

In England at the present time outbreaks of dysentery chiefly affect asylum populations, and these are almost always caused by the Bacillus dysenteriae of the Flexner type. In one asylum outbreak in England and in an epidemic in Scotland Shiga's bacillus has been isolated.

Almost all the cases of dysentery returning from Gallipoli are of the bacillary variety, and the experience of Ledingham, Penfold, and Woodcock ${ }^{1}$ appears to show that the infection is chiefly with the Shiga bacillus, while in a smaller number the Flexner bacillus is present. From the eastern Mediterranean a few cases of infection with the Entamoeba histolytica have been reported. Among the French in the

\footnotetext{
1 See Brit. Med. Journ., November r3, 1915, p. 704

No. 2406, VOL. 96]
}

Argonne the large majority of the numerous cases occurring there are due to the $\mathrm{Y}$-bacillus of Hiss and Russell. In the Germany army on the west front cases due to the Flexner bacillus are reported, while among the Austrians infection with the Shiga bacillus is met with.

In the treatment of amœbic dysentery emetine, an alkaloid of ipecacuanha, is practically a specific, and for the bacillary form anti-dysentery serum is very successful.

Outbreaks of dysentery in armies raise many important problems for the sanitarian. The disease is partly water-borne, though, of course, there is considerable opportunity for direct contamination of food and person in camp and trench life. The intestinal evacuations of cases contain vast numbers of dysentery bacilli and, unless disinfected, infect the locality, particularly the trenches and their neighbourhood, where the men are attacked before removal to hospital, while infection may be spread far and wide owing to the fact that the bacillus does not necessarily disappear from the patient with the onset of convalescence, but may remain in the body for a long time after cessation of symptoms, so that the "carrier" state becomes established. It would probably be desirable to regard a case as possibly infective for a period of three months after the termination of the attack, but the exigencies of war may prevent such a course. Bacteriological examination ought also to be carried out so far as possible to determine when an individual has ceased to be a "carrier."

At present a high standard of general and personal hygiene is the best preventive of the disease. Attempts have been made to introduce preventive inoculation against bacillary dysentery, but with what success is not yet known.

R. T. HEWLETT.

\section{OILS AND FATS AS WAR SUPPLIES.}

THE discussion in the House of Commons last week, on the export of oils to neutral countries bordering on Germany dealt with a matter on which scientific knowledge might have been brought to bear with great national advantage.

There is no doubt that fats are the one material that a country situated in northern Europe must procure from without; indeed, the price of oils current in Germany affords complete testimony of the accuracy of this statement. Fats are of value for two purposes: first, as an altogether indispensable article of food, and, secondly, as a source of glycerine, which is converted into nitroglycerine and becomes an ingredient of all propellent explosives. Apart from tallow, and perhaps some small amount of linseed, Germany produces no other fat, and her stocks could have lasted but a limited time only. The deficiency has been made up by imports from tropical lands through neutral countries, which, so long as we have control of the seas, can only be obtained by favour of Great Britain.

One by one restrictions have been placed on 